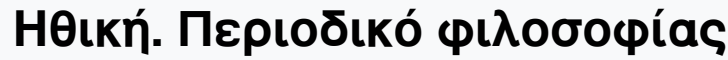

Ap. $13(2020)$

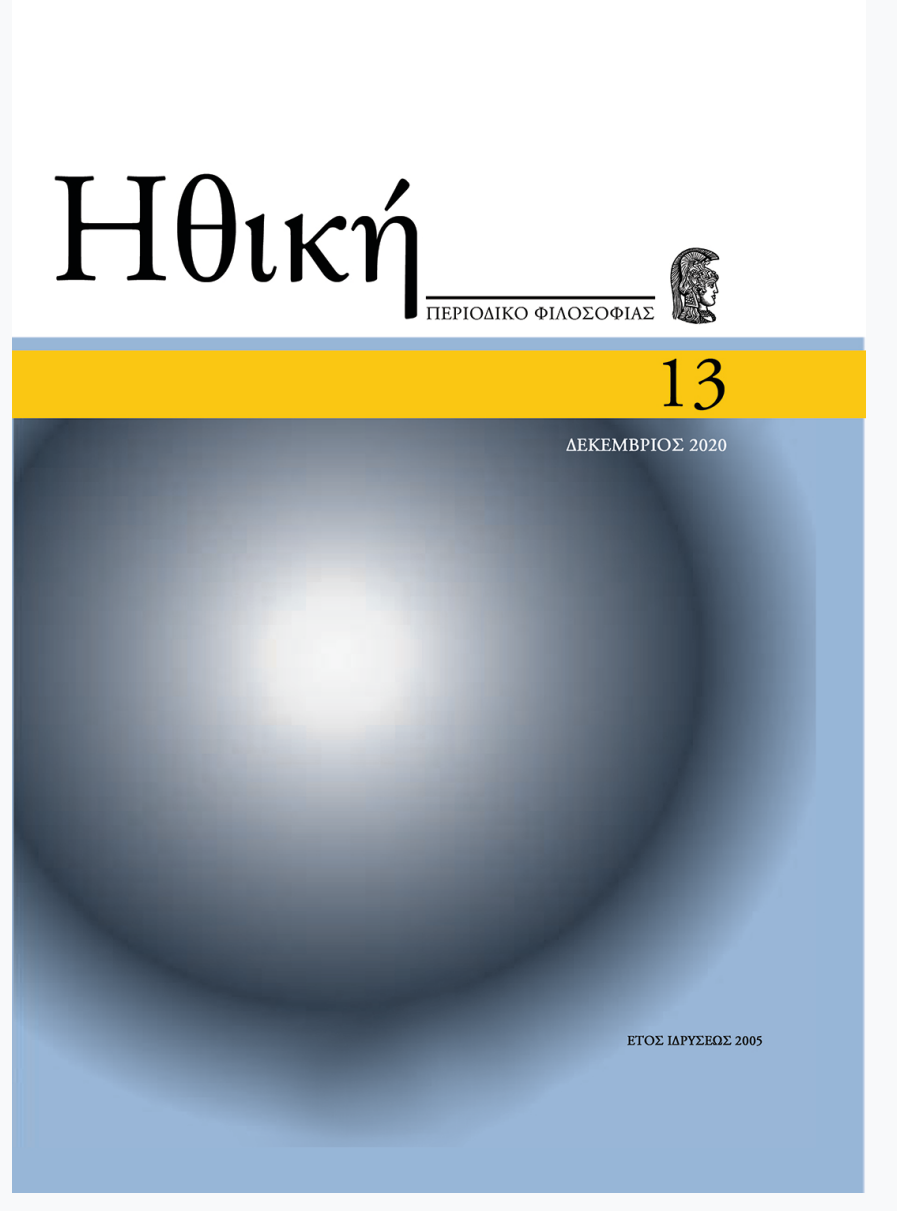

Bionic man: Principles and limits

George Roumeliotis

doi: $\underline{10.12681 / \text { ethiki.25985 }}$

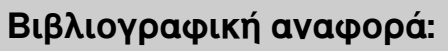

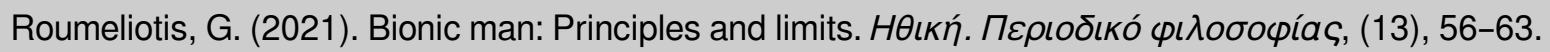
https://doi.org/10.12681/ethiki.25985 


\title{
Bionic man: Principles and limits
}

\author{
George Roumeliotis
}

National and Kapodistrian University of Athens https://orcid.org/0000-0002-9328-0536

\begin{abstract}
The subject of this paper is the ethical considerations raised in the issue of "bionic man", a man whose many organs have been replaced by artificial, and the principles and ethical limitations that are inherent in this process. Four basic bioethical principles are acknowledged in the international bibliography: a) the principle of beneficence; b) the principle of autonomy and informed consent of patients; c) the principle of justice; d) the principle of equality. Apart from this, some more issues should be taken into consideration in the discussion about the ethics of artificial implants: the allocation of health care and economic resources, the patentability of implants, the use of implants in the human consciousness itself and the subsequent changes of implants in one's personality, as well as the willingness of a patient to accept an implant under the prism of his/her belonging to a specific subculture, due to his/her impairment.
\end{abstract}

Keywords: artificial implant; ethics; 'four-principles' approach; autonomy; moral considerations

\section{Introduction}

The subject of this short text is the "bionic man", a man whose several organs have been replaced by artificial ones, and the principles and ethical limitations that are inherent in this process. I will approach the issue as a doctor because of my status as an orthopedic surgeon. Many people say that the best place to hide a note from a doctor is a philosophy book, although it is hard to find a philosophy book in a doctor's office. But as you try to evade the philosophy and focus on money, the medical practice itself brings him face to face with a series of philosophical questions. Whenever for example someone is facing a major car accident with the patient's life at risk, a limb injury threshold for amputation, the patient may not be able to decide for himself and his relatives may be unable to understand the situation, then he is automatically converted into a practical and usually self-taught moral thinker given the absence of theoretically trained persons (moral philosopher, legislator and judge) from the field. Somebody must decide not only whether to amputate or not, what materials will be used to repair or replace a joint, but also if he will tell the whole truth or not to the relatives of the patient. But, even more complex is in how much risk he will put the patient's life to save a limp, if the repair or replacement of a joint will provide better quality of life to the patient in the future and what percentage of truth is ready to face 
anyone of the relatives. The situation gets even more complicated by the fact that the biological phenomena do not necessarily obey the Cartesian logic and in biology one plus one equals very often two ... but not always.

Man always used objects from nature and technological advances to make life easier without ethical concerns, so once the technology and medical technique allowed these items to replace parts of his body, the medicine incorporated them in practice adopting only the simple principle "Help or no harm." Some of the implants replace the entire body while others only a part or a function. Some need to be replaced later, while others can stay permanently. Some of them may be implanted completely, while others are quite large and a part of them can be located outside the patient's body. Bones, teeth, joints, blood vessels, nerves, kidneys, sensory organs, the heart (with which by the way you can fall in love as would happen with a real one), gastrointestinal system and even the brain can be replaced partly or wholly.

The use of medical inserts may seem simple compared to transplantation, but raises a number of ethical issues. I will briefly mention a few of them. A first subject of matter is the property of the implant. Does it belong to the patient that is using it, to the insurance fund that has paid for for it or to the company that manufactured it? Before you can answer the obvious invoking the autonomy of a person and the right of self-determination, think. Is for example the pension system entitled to require regular radiological control of the implants and as a penalty disrupt the patient's retirement program? Would you approve the revision of an arthroplasty that was manifestly destroyed by misuse or would you impose similar restrictions to those that exist for alcoholics in need of liver transplant?

But also what are the legal obligations of the manufacturer in case of construction errors found after installation? A second and very hot topic is the accessibility of patients in inserts. In health before any other field, applies the basic principle of economy that "needs are unlimited while resources are limited." Who has the six million dollars in 1980 values required to create the first bionic man according to American television mythology? To get real who decides the priority of patients as far as the use of implants is concerned? The third and more complex dilemma is the effect of the use of implants in the human consciousness itself. I would certainly be out of subject if I tried to answer the question of how the human consciousness is formed but the assumption that the use of an implant could change the human consciousness makes the issue at least morally complicated. This debate was intensified about the use of cochlear implants. The installation for example of a childhood cochlear implant in one of the deaf twins of a mixed couple of deaf and not deaf could lead to radically different consciousness forming of the children when they become adults and their total interest may be assessed differently depending on their different individual theoretical approach to the subject of deafness.

To solve the issue of rationality of medical decisions, we doctors rely today on the "medical evidence" actually replacing personal experience with statistics and thus shifting personal responsibility to collective experience. Similarly, bioethics can use social research in determining the overall benefit gradually becoming more empiri- 
cal and less dogmatic as a scientific field. In an era that biotechnology and genetics promise the manufacture of biological implants, the use of simple mechanical implants is considered daily routine. From this everyday use, we draw moral conclusions that will be used for more complex bioethical issues such as transplants and biotechnological developments.

\section{Bioethical principles and limits}

Four basic bioethical principles are acknowledged in the international bibliography: a) the principle of beneficence; b) the principle of autonomy and informed consent of patients; c) the principle of justice; d) the principle of equality. This 'four-principles' approach was at first introduced by Beauchamp in 1976 in his work entitled "The Principles of Biomedical Ethics" and was analyzed by professor Gillon in his book "The Principles of Health Care Ethics" in 1994, who claimed that (Gillon, 1994, xxii):

the four principles plus scope approach claims that whatever your personal philosophy, politics, religion, moral theory or life stance, you will find no difficulty in committing yourself to four prima facie moral principles plus a concern for their scope of application. Moreover, these four principles plus attention to their scope of application can be seen to encompass most if not all of the moral issues that arise in health care [...] The four principles approach does not claim to provide a method for doing so [...] What the principles plus scope can provide is a common set of moral commitments, a common moral language, and a common set of moral issues to be considered in particular cases, before coming to your own answer, using your preferred moral theory or other approach to choosing between these principles when they conflict ${ }^{1}$.

According to the principle of beneficence and non-maleficence, medical and nursing staff must act in favor of the patient and not cause any harm. Therefore, the moral correctness of an act is determined in terms of the benefit it brings to the individual and whether it has caused a harm or not $^{2}$ (Akinosoglou et al., 2007, 164; Katsimigas and Vasilopoulou, 2010, 606; Hope, 2004, 65; Sommerville, 2013, 4). Consequently, at this point the issue of health risk is raised ${ }^{3}$ (Krishna, 2007, 121). Health risk is involved in every case of transplantation and thus there is a level of probability of a damaging event that could cause harm or put the patient's health at risk (e.g. infection), or a probability of transplant rejection. This is even more important in the case a (probably new) proposed therapy is based only in hypotheses, due to insufficient reliable statistics from previous experience. Another issue related to this principle is the assumption that the moral duty of beneficence is involved in every profession, since all professionals' actions aim at some good, according to Aristotle as well ${ }^{4}$ (Downie and Macnaughton, 2007, 40). This means that the principle of beneficence is actually an inherent characteristic of all professions, among which the medical one. 
However, one should acknowledge the fact that the medical profession presents some ethical considerations that do not exist in other types of businesses, since it is related to human health and life, and for this reason this principle is far more important.

Another important issue with which the medical world deals for centuries within the context of bioethics is whether the physician can act in the name of his medical science and education without asking for the patient's consent, or if it is required to inform the patient and act on the right of individual choice ${ }^{5}$ (Krishna, 2007, 123). Therefore, one of the major issues of medicine is the limits of the clinical autonomy of doctors and the right of patients' informed consent. According to the principle of autonomy, the patient has the right to make decisions on his own, freely, without being impeded, but also in accordance with the principles of a democratic society ${ }^{6}$ (Akinosoglou et al., 2007, 163). That is, the principle of autonomy pay emphasis on patient's right to have control over his own life $^{7}$ (Hope, 2004, 93). The respect for autonomy includes the following principles ${ }^{8}$ (Wise, 2002; Hope, 2004, 94): a) telling the truth, b) respect for the individuality, c) protection of confidential information, d) obtaining consent for any patient intervention and finally e) helping patient to make important decisions when requested.

The ethical principle of patient autonomy governs the relationship of the physician with the patient and one could claim that it implies the information of the latter by the medical and nursing staff' (Mollaki, 2014, 105). However, the significant decline of medical paternalism today for the benefit of individual autonomy, in some cases seems justified or necessary, or at least inevitable, given the nature of the medical profession as mentioned above through the example of 'bionic man'. Therefore, contrary to the view that patients and citizens in general must be aware of ethical issues, there is the view that patient's informed consent principle, which is based on the principle of respecting the patient's individual autonomy, cannot determine the appropriate limits of the clinical autonomy of doctors ${ }^{10}$ (Mollaki, 2014, 110).

In the discussion about the concept of patient's autonomy and respect to his rights, we should refer to the Kantian moral philosophy, that distinguishes between the moral imperatives related to oneself and other. In the first case, the judgment about what the doctor should do, with regard to the information disclosure to the patient, derives from his own adoption of a universalistic perspective about the moral law and respect for the other, that Kant refers to as 'the autonomy of the will'. In the second case, the provision of information to the patient and the right of the latter to respect is regarded more as an obligation, since it is imposed by external determinants (e.g. legislation), which Kant called 'heteronomous'. Putting all the above together, a doctor may provide a treatment not because it is necessary or beneficial in medical terms, but because it is patient's will, and thus it respects the patient's autonomy ${ }^{11}$ (Downie and Macnaughton, 2007, 41). The debate that is raised concerns the medical justification of adopting this view. One possible question regards whether the patient is in position to know what is good for his own health and life. Within this framework, the concept of autonomy is rather narrowed down to what patient wants, if one assumes that the patient does not have the knowledge and ability to choose 
what is good for his health. The second debate concerns the case when self-governing is not feasible, and thus the doctor should take a decision about a patient's life and death on his own, or whether a doctor has the right to deny a patient's request when it is not at the right direction, namely for the patient's safety and interest ${ }^{12}$ (Sommerville, 2013, 24). At this point, the doctor should show respect for his patient, but the concept of respect is subjected to multiple interpretations, based on subjective judgments and cultural values. Overall, the principle of autonomy and respect is complex, since on the one hand it may be related to actions according to the patient's wants, and on the other according to the patient's interests, irrelevant of his wills, based on the respect on human life.

At this point the principle of justice comes in the forefront. According to this principle, which derives from the Hippocratic Oath, every person should be able to satisfy his or her health needs. More specifically, the principle of justice states that every patient is entitled to his or her own ${ }^{13}$ (Akinosoglou et al., 2007, 164; Hope, 2004, 65). At first, this principle can be seen under the perspective of the relationship between autonomy and self-determination ${ }^{14}$ (Sommerville, 2013, 3), according to which everyone should do whatever wants with his / her body, which leads to the discussion about morality in the context of body integrity, which in turn is linked to human dignity ${ }^{15}$ (Roosendaal, 2012a, 84). However, Fukuyama has stated that "the kind of moral autonomy that has traditionally been said to give us dignity is the freedom to accept or reject moral rules that come from sources higher than ourselves, and not the freedom to make up those rules in the first place"16 (Roosendaal, 2012a, 86). Second, the principle of justice is directly related to the principle of equality, since individuals' health needs should be fully satisfied without any discrimination. In particular, all patients should be treated equally unless there is a special medical reason justifying something different ${ }^{17}$ (Akinosoglou et al., 2007, 164).

The principle of justice is also related to the allocation of health care resources, which is another important ethical consideration in the medical practice of implants ${ }^{18}$ (Downie and Macnaughton, 2007, 34). The ethical validity of artificial implants is often questioned, since it requires a great outlay of health care and economic resourc$\mathrm{es}^{19}$ (Krishna, 2007, 124). Especially if one takes into account also the risk, the case of 'bionic man' is even more questionable. Indeed, in cases where the implants are new and not tested, the effects may not be clear and a priori known ${ }^{20}$ (Roosendaal, 2012, 72). At this point, the justification of transplantation lies on the urgent need to save a life in the light of the lack of other alternatives. Even in the case where there is no previous experience and the health risk is greater, the motto 'for the sake of science' in the name of future patients may be used to justify the allocation of resources in this action. Thus, in this cost-benefit analysis, the potential future benefits for medical knowledge, and subsequently for the patients, should be taken into consideration. Apart from this, one should examine the current cost of alternative treatments. In the case the cost is higher than that of an artificial implant, then perhaps this could serve as a further justification ${ }^{21}$ (Krishna, 2007, 124). In this discussion, the concept of justice should also incorporate the concept of utility, which refers to the maximi- 
zation of the benefits for the population ${ }^{22}$ (Downie and Macnaughton, 2007, 94; Sommerville, 2013, 3). Hence, the debate raised concerns the priorities that are set and the public interest and upon which the resource allocation in the health care sector is largely based.

One more issue should be mentioned at this point: the patentability of implants ${ }^{23}$ (Krishna, 2007, 124). In the case of artificial implants, their property rights are one more interesting question. Private organizations and companies have invested huge amounts of money and have dedicated much effort to create an artificial implant, while in some cases they have also been funded by public institutions. In this process, these organizations and companies expect some profit for their investment, usually by acquiring patents. However, in the case of a 'discovery', there is no issue of patent ${ }^{24}$ (Krishna, 2007, 58). Apart from this, the principle of equality and justice is one more obstacle in providing an adequate answer to the question about the property rights of an artificial implant.

Apart from the above, one more issue that should be addressed is the impact of the use of implants in the human consciousness itself. It is argued that treatment may cause changes in one's personality ${ }^{25}$ (Hansson, 2000, 523). This raises issues in the field of moral philosophy. There are two views in this debate. The first is the utilitarian one, according to which value is assigned to the mental state entertained by a person and not to the person itself. On the other side, deontological and rights-based ethics focus on the person. Thus, under these ethical viewpoints, the continuity of a person's identity is significant for the satisfaction of moral demands. Despite the fact that personal identity may not be a subject of primary concern compared to a patient's life, the change in one's personality and consciousness may actually be. These changes may occur because of artificial brain implants, or from some infection, or even from the change in one's life after the implant. Human consciousness is of great significance for one more reason: because it shapes the boundaries between self and others.

The way the society and significant others value and perceive the morality of implants and the changes occurred in one's life and health after it, may guide the discussion about human consciousness in one more field, that of a subculture ${ }^{26}$ (Hansson, 2000, 524). People with special needs, such as deaf people, have formed minority cultural groups based upon their impairment. In the case of deaf people, for example, cochlear implants are not compatible with the established medical ethics, whereas they can put the culture of deaf people at risk, because they belong to the so-called' deaf-community'. Hence, social and cultural notions related to impairment should be taken into account in the ethical discussion about implants in such groups of people. The improvement in one's health and life can give rise to the creation of other subcultures, involving people with implants. This can be related to the former discussion about the way the society regards the concept of normality, since these people may be considered as 'subnormal', being attached to a specific group, without being able, or even willing ${ }^{27}$ (Christiansen and Leigh, 2002, 253; Hope, 2004, 54; Sommerville, 2013, 27), to be included in the group formed by 'normal people'. 


\section{Conclusions}

The Universal Declaration of Human Rights, introduced in 1948, recognizes the inherent dignity, as well as the equal and inalienable rights of all people. The concept of patients' rights has been developed precisely on the basis of this concept of dignity and equality / justice for all people. In addition, patients' rights are based on the right of all people to health care treatment, as it is stated in Article 12 of the International Pact on Economic, Social and Cultural Rights produced in 1996 by the United Nations.

However, it should be mentioned that apart from the international conventions, there are national laws and legislations, as well as some 'soft' laws, or else unspoken rules. The reason is that patients' rights vary in different countries, depending on prevailing cultural and social norms. In addition, different patterns of the relationship between patient and doctor have evolved, which play an important role in the recognition of patients' rights. These patterns change over time, reflecting social, cultural, economic and historical changes.

All the above should be taken into consideration in the moral debate on artificial implants. There are often cases where the rights of patients conflict with the obligations and duties on behalf of the doctors ${ }^{28}$ (Sommerville, 2013, 10). The rapid evolution of science and technology has led to the introduction of new medical methods and practices that provide more options and alternatives to patients, and which, at the same time, raise important questions about the limits of patients' autonomy, doctors' obligations, patient information, respect to human dignity, and public interest.

The aim of this paper was to discuss some of the most significant ethical considerations raised in the field of artificial implants. Of course the questions posed at this paper and the subsequent discussion do not cover all the moral aspects of the issue of artificial implants, but it is a rather fair discussion about this issue and the basic guidelines that should be used in order to deal with this debate. In an effort to summarize this debate, two important theories emerge. The first is utilitarian ethics, according to which a doctor should act on the basis of the patient's interest, taking also into account the public interest. The second is deontological ethics, where a doctor's actions aim at the preservation of the autonomy, the body integrity and the self-determination of the patient. Of course, the societal norms, the various subcultures and the subjective judgments about right and wrong, constitute significant features of such a debate. With the rapid expansion of medical knowledge and biotechnology, such discussions will inevitable be more at the forefront, as the cornerstone of medical practice. Hence, this is rather a non-conclusive discussion, with which we will be constantly dealing in the future.

\section{REFERENCES}

1. Raanan Gillon, The Principles of Health Care Ethics, John Wiley \& Sons, Chichester England - New York, 1994, xxii.

2. K. Akinosoglou, E. Apostolakis and D. Dougenis, 2007. "Patient's rights and who is to protect them", Archives of Hellenic Medicine 24 (2007): 164, George Katsimigas and Georgia Vasilopoulou, 
"Basic principles of bioethical and orthodox ethics", Vima Asklipiou 9 (2010): 606, Tony Hope, Medical ethics. A very short introduction, Oxford University Press, Oxford, 2004, pg. 65, Ann Sommerville, Everyday Medical Ethics and Law, John Wiley \& Sons, West Sussex, 2013, pg. 4.

3. Sree V. Krishna, Bioethics and biosafety in biotechnology, New Age International, New Delhi, 2007, pg. 121.

4. Robin S. Downie and Jane Macnaughton, Bioethics and the humanities: Attitudes and perceptions, Routledge, Oxon, 2007, pg. 40.

5. Sree V. Krishna, ibid., pg. 123.

6. Akinosoglou et al., ibid., 163.

7. Tony Hope, Medical ethics. A very short introduction, pg. 93.

8. Debbie Wise, "Exploring the Role of Health Professionals in Truth Telling: A Nursing Perspective", 2002. Accessed April 20. http://www.nathaniel.org.nz/component/content/article/13-bioethical-issues/ what-is-bioethics/90-exploring-the-role-of-health-professionals-in-truth-telling-a-nursing-perspective. Tony Hope, ibid., pg. 94.

9. Vassiliki Mollaki, Reflections on contemporary issues 2008-2013. Hellenic National Bioethics Commission, National Printing Office, Athens, 2014, pg. 105.

10. Ibid., pg. 110.

11. Robin S. Downie and Jane Macnaughton, ibid., pg. 41.

12. Ann Sommerville, Everyday Medical Ethics and Law, pg. 24.

13. Akinosoglou et al., ibid., 164, Tony Hope, ibid., pg. 65.

14. Ann Sommerville, ibid., pg. 3.

15. Arnold Roosendaal, "Implants and Human Rights in Particular Bodily Integrity" in Human ICT Implants: Technical, Legal and Ethical Considerations, edited by Mark N. Gasson, Eleni Kosta and Diana M. Bowman, T.M.C. Asser Press, The Hague, 2012a, pg. 84.

16. Ibid., pg. 86.

17. Akinosoglou et al., ibid., 164.

18. Robin S. Downie and Jane Macnaughton, ibid., pg. 34.

19. Sree V. Krishna, ibid., pg. 124.

20. Arnold Roosendaal, "Carrying Implants and Carrying Risks; Human ICT Implants and Liability" in Human ICT Implants: Technical, Legal and Ethical Considerations, edited by Mark N. Gasson, Eleni Kosta and Diana M. Bowman, T.M.C. Asser Press, The Hague, 2012, pg. 72.

21. Sree V. Krishna, ibid., pg. 124.

22. Robin S. Downie and Jane Macnaughton, ibid., pg. 94, Ann Sommerville, ibid., pg. 3.

23. Sree V. Krishna, ibid., pg. 124.

24. Sree V. Krishna, ibid., pg. 58.

25. S. O. Hansson, "Implant ethics", Journal of Medical Ethics 39 (2000): 523.

26. Ibid., 524.

27. John Christiansen and Irene W. Leigh, Cochlear Implants in Children. Ethics and Choices, Gallaudet University Press, Washington, 2002, pg. 253, Tony Hope, ibid., pg. 54, Ann Sommerville, ibid., pg. 27. 28. Ann Sommerville, ibid., pg. 10. 